\title{
O leite de búfala
}

\section{The buffalo milk}

\section{Resumo}

A produção de leite se destaca como uma das principais aptidões das búfalas e é considerada de grande importância em vários países. O mercado para os derivados do leite de búfala está em franca expansão no Brasil. Esses produtos, principalmente a muçarela e a ricota, são procurados não só por seu sabor característico, mas também por suas qualidades nutricionais. As búfalas são consideradas menos susceptíveis à mastite do que as vacas, embora os microrganismos envolvidos na infecção sejam semelhantes. Este artigo aborda aspectos relacionados ao leite de búfala, destacandose produção, características físico-químicas e microbiológicas.

\section{Summary}

Milk production stands out as one of the main skills of buffaloes, and is considered to be very important in several countries. The market for buffalo milk products is fast growing in Brazil. These products, specially the Mozzarella and the Ricotta cheese, are acquired not only because of their particular taste, but also for their nutritional qualities. The buffaloes are considered less susceptible to mastitis than cows, even though the microorganisms involved in the infection are similar. This article describes several aspects of buffalo milk, particularly production, physico-chemical and microbiological characteristics. 
Faculdade de Medicina Veterinária e Zootecnia,

UNESP, Campus de Botucatu.

Botucatu, Brasil - 18618-970.

■iseledelaricci@hotmail.com

\section{Introdução}

Os búfalos, como os bovinos, são classificados zoologicamente

Búfalas. Leite. Produção.

Keywords

Buffaloes. Milk. Production. como família Bovidae e subfamília bovinae. Os bovinos pertencem à espécie Bos taurus e os búfalos a Bubalus. Dentro desta, encontram-se três subespécies, Bubalis, Kerebau ou Carabao e Fulvus. A espécie Bubalus também é classificada como Búfalo de água ( $B u$ balus bubalis bubalis) e de pântano (Bubalus bubalis karebau). Atualmente, o búfalo é encontrado em todos os continentes (JORGE et al., 2011).

A produção leiteira destaca-se como uma das principais aptidões das búfalas, e é considerada de grande importância em vários países. Na Ásia, o búfalo tem papel fundamental na agricultura, podendo ser criado em pequenas propriedades, onde é considerado provedor de alimentos (NASCIMENTO e CARVALHO, 1993; AMARAL et al., 2005).

Os principais países asiáticos produtores de leite bubalino em ordem de importância são: Índia, Paquistão, China, Nepal, Iran, Mianmar (ex Birmânia) e Vietnã (FAO, 2007 apud JORGE et al., 2011).

$\mathrm{Na}$ Índia, embora o rebanho bubalino seja somente $24 \%$ do rebanho total de bovinos e bubalinos, cerca de $60 \%$ do leite produzido nesse país é de búfala. No Brasil, sua contribuição também é de grande importância em pequenas e médias propriedades rurais (NASCIMENTO e CARVALHO, 1993; AMARAL et al., 2005).

A búfala tem grande potencial como animal para produção de leite, apresentando o teor de seus constituintes com maior valor

1 Acadêmica do $4^{\circ}$ ano do Curso de Zootecnia - Faculdade de Medicina Veterinária e Zootecnia UNESP, Campus de Botucatu.

2 Professor Adjunto do Departamento de Higiene Veterinária e Saúde Pública - Faculdade de Medicina Veterinária e Zootecnia, UNESP, Campus de Botucatu. 
nutritivo e rendimento industrial quando comparados com o leite de vacas; além da sua maior rusticidade, o que permite a criação em regiões alagadas, que são inadequadas para bovinos (AMARAL et al., 2005).

O objetivo deste artigo é discorrer sobre produção, características físico-químicas e microbiológicas do leite de búfalas.

\section{Produção e características do leite de búfala}

Atualmente, o búfalo pode ser encontrado em todos os países do continente americano, sendo o Canadá e o Chile os últimos a incorporar esta espécie. Os principais países, em quantidade de cabeças são: Brasil, Venezuela, Colômbia e Argentina (JORGE et al., 2011).

Os dados publicados em 2010 pelo MAPA - Ministério da Agricultura, Pecuária e Abastecimento (BRASIL, 2010) apresentam valores de um efetivo de 1.207.461 búfalos, sendo estes distribuídos pelas cinco regiões do país, respectivamente nas seguintes quantidades e proporções: Norte: 820.295 (67,93\%); Sudeste: 115.404 (9,55\%); Nordeste: 112.053 (9,28\%); Sul: 105.264 (8,71\%) e Centro-Oeste: 54.445 (4,50\%); destacando-se as seguintes raças: Murrah; Jafarabadi e suas cruzas; Mediterrâneo; e Carabao. Entretanto, Jorge et al. (2011) citam que o Brasil possui o maior rebanho de búfalos da América, com cerca de 4 milhões de cabeças, um número superior ao descrito pelo MAPA. Sua produção vai desde a venda de carne e de leite até seus subprodutos, além disso, é utilizado na região do Amazonas para trabalho.

Teixeira et al. (2005) relatam que a Itália é o país mais desenvolvido em produção leiteira de búfalos e seus derivados. Silva et al. (2003) destacam que neste país, se encontra a maior produção de leite de búfala da Europa e que sua quase totalidade é destinada à elaboração de muçarela.

Segundo a FAO (2007), a produção mundial de leite de todas as espécies no ano de 2005 alcançou 629,2 milhões de toneladas, das quais $12,2 \%$ foram de búfala (JORGE et al., 2011).

No Brasil ocorre um aumento crescente na criação de búfalos, principalmente para a produção leiteira, em decorrência das características físico-químicas peculiares do leite (MESQUITA et al., 2002).

O mercado para os derivados do leite de búfala está em franca expansão no Brasil. Estes produtos, em especial a muçarela e a ricota, são procurados não só por seu sabor característico, mas também por suas qualidades nutricionais (TEIXEIRA et al., 2005).

Nos últimos cinquenta anos, o crescimento da produção de leite de búfala foi de 301,0\%, ao contrário do leite de vaca que nesse mesmo período alcançou apenas $59,3 \%$, o de leite de cabra $85,0 \%$ e o de ovelha $54,5 \%$, o que sinaliza indiscutivelmente a importância da evolução da bubalinocultura leiteira (JORGE et al., 2011).

Atualmente, em relação ao volume de leite produzido, o leite de búfala ocupa o segundo lugar em importância, depois do leite de vaca, seguido pelo de cabra e o de ovelha, que ocupam o terceiro e quarto lugares respectivamente (Tabela 1).

De acordo com Silva et al. (2003) o leite de búfala é cerca de 40-50\% mais produtivo na elaboração de derivados (queijos, iogurte, doce de leite, entre outros) que o leite bovino. Por conter um teor de gordura maior, são necessários apenas 14 litros de leite de búfala para produzir $1 \mathrm{Kg}$ de manteiga, ao passo que para obter a mesma quantidade de manteiga com leite de vaca, são necessários mais de 20 litros. Por outro lado, com apenas 5,o litros de leite de búfalas pode-se obter $1 \mathrm{Kg}$ de queijo muçarela de alta qualidade.

O leite de búfala apresenta características que o diferenciam de qualquer outro tipo de leite. Seus valores de lipídeos, proteínas, lactose, sólidos totais e resíduo mineral fixo são de grande importância nutricional. A ausência de $\beta$-caroteno na composição química do leite

\begin{tabular}{|c|c|c|c|c|c|c|}
\hline \multicolumn{7}{|c|}{ ANOS } \\
\hline ANIMAL & 1965 & 1975 & 1985 & 1995 & 2005 & $\begin{array}{l}\text { CRESCIMENTO } \\
\text { NO PERIODO (\%) }\end{array}$ \\
\hline Bovino & 332,5 & 387,7 & 458,0 & 464,4 & 529,8 & 59,3 \\
\hline Bubalino & 19,2 & 23,2 & 37,0 & 54,4 & 77,0 & 301,0 \\
\hline Caprino & 6,7 & 6,6 & 8,3 & 11,7 & 12,4 & 85,0 \\
\hline Ovino & 5,5 & 5,8 & 7,2 & 7,9 & 8,5 & 54,5 \\
\hline Outros & 0,9 & 1,2 & 1,4 & 1,4 & 1,5 & 66,6 \\
\hline Total & 364,8 & 424,5 & 511,9 & 539,8 & 629,2 & 72,4 \\
\hline
\end{tabular}

Fonte: FAO (2007), citado por JORGE et al., 2011.

TABELA 1 - Produção mundial de leite por espécie (milhões de toneladas). 
de búfala é uma das principais características, conferindo-lhe coloração branca. É mais concentrado que o leite bovino, apresentando assim menos água e mais matéria seca. Outra característica é possuir um sabor bem adocicado, apesar de não possuir mais lactose que o leite bovino. Seu alto teor de cálcio faz com que seja recomendado contra a osteoporose. É vital no processo de recuperação de pacientes em luta contra doenças de todos os tipos, que precisam ingerir alimentos de qualidade em pequenas doses ao longo do dia (DUBEY, 1997; MACEDO et al., 2001).

A lactose é o principal açúcar do leite, servindo de base para a obtenção dos derivados por meio da fermentação. Em bubalinos, os teores de lactose apresentam valores entre 4,83 e 5,48\% (SINDHU e SINGHAL 1988; DUARTE et al., 2001).

A gordura é o constituinte do leite que apresenta maior valor econômico, sendo utilizada na produção de derivados, contribuindo para o sabor característico e melhorando a textura dos mesmos. Sob o ponto de vista nutricional, os lipídeos apresentam níveis apreciáveis de ácidos graxos essenciais ao organismo (OLIVEIRA, 2004). É o mais variável e um dos mais importantes componentes do leite, oscilando em média, entre $5,5 \mathrm{e}$ $8,5 \%$ nos bubalinos (TONHATI et al., 2000; DUARTE et al., 2001; ROSATI e VAN VLECK, 2002), valores estes, mais elevados que os encontrados no leite de vaca.

A acidez titulável do leite da búfala apresenta valores ligeiramente superiores à acidez titulável do leite da vaca, isto provavelmente ocorre em função da maior quantidade, diâmetro e número das micelas de caseína do leite da búfala em relação ao leite da vaca (MACEDO et al., 2001).

A densidade encontrada para o leite bubalino é similar à encontrada no bovino. Comparando a densidade do leite de diferentes raças, Tonhati et al. (1998) obtiveram uma variação de densidade entre 1,0320 e 1,0374 $\mathrm{g} / \mathrm{ml}$. Em relação ao ponto de crioscopia encontraram variações, para diferentes raças, com valores entre $-0,552^{\circ} \mathrm{C}$ e $-0,512^{\circ} \mathrm{C}$.

A composição do leite de búfala apresenta características físico-químicas próprias, que variam conforme o período de lactação, a raça e a alimentação, entre outros fatores (TEIXEIRA et al., 2005).

$\mathrm{Na}$ composição do leite de búfala são encontrados muitos nutrientes essenciais para a dieta humana, sua microbiota natural o torna um excelente meio para o crescimento de microrganismos, o que faz com que seja perecível, necessitando de processos tecnológicos adequados, capazes de garantir sua integridade e proteger sua capacidade como matéria-prima essencial para produção de derivados (FREITAS, 2001; GONÇALVES e VIEIRA, 2002; AMARAL et al.,2005).

O estado de saúde e a alimentação exercem grande influência sobre a produção e a qualidade do leite, pois, se o animal for acometido de alguma doença ou se a dieta fornecida não lhe atender às exigências nutricionais necessárias, todo o metabolismo do animal fica comprometido, acarretando em diminuição na produção e principalmente, nos níveis de gordura e proteína do leite.

Santa Rosa (2011) destaca que falta uma legislação federal específica para determinar o padrão de identidade e qualidade do leite de búfala. Entretanto, a Secretaria de Agricultura e Abastecimento (SAA) do Estado de São Paulo publicou uma resolução válida para o estado de São Paulo, que estabeleceu valores de $\mathrm{pH}$ (entre 6,40 e 6,90 ), acidez Dornic ( 14 a $23{ }^{\circ} \mathrm{D}$ ), gordura (mínimo de $4,5 \%$ ), extrato seco desengordurado (mínimo de $8,57 \%)$, densidade a $15^{\circ} \mathrm{C}$ (de 1,028 a 1,034$)$ e índice crioscópico $\left(-0,520\right.$ a $\left.-0,570{ }^{\circ} \mathrm{C}\right)$ para caracterização de leite bubalino normal (SÃO PAULO, 1994). A SAA não fez referências aos teores de lactose, proteína, sólidos totais, porém, estabeleceu a proibição de adição de leite de outras espécies de animais ao leite de búfala.

Para a utilização do leite bubalino e derivados na alimentação humana é necessário que estes apresentem boas condições higiênico-sanitárias em todas as etapas de produção, visando evitar a presença de microrganismos patogênicos e/ou deteriorantes nos produtos finais. Também é importante que as características sensoriais e físico-químicas sejam avaliadas para garantir produtos com alto valor nutricional, qualidade e alta aceitabilidade pelo mercado consumidor (CUNHA NETO et al., 2005; FARIA et al., 2006).

\section{Microbiologia do leite}

Um alto conteúdo microbiológico diminui a vida útil do leite e causa perdas em produtos derivados, além de riscos elevado à saúde pública. Essa microbiologia característica é o fator mais importante para o sucesso da industrialização e fabricação de seus derivados, interessando tanto aos laticínios, o que gera aumento significativo no preço do leite, quanto aos consumidores, que por sua vez, adquirem produtos de melhor qualidade.

Microbiologicamente, a qualidade do leite de búfala está intimamente relacionada aos hábitos do animal e ao manejo da ordenha. Um fator de relevância é o comportamento do animal de imergir em coleções de água à procura de conforto térmico. Tal hábito dificulta a higienização do úbere da búfala (TEIXEIRA et al., 2005). Cunha Neto (2003) cita a presença de microrganismos 
mesófilos no leite de búfala in natura, de acordo com a estação do ano, encontrando valores entre 5,0 x 104 a 1,3 x $103 \mathrm{UFC} / \mathrm{ml}$ no inverno, e 1,5 x 105 a 3,2 x 107 UFC/ $\mathrm{ml}$ no verão, o que caracteriza uma alta contagem microbiológica, apresentando risco potencial para a saúde pública, reduzindo a vida útil do leite, e resultando em perda na qualidade dos produtos.

Os microrganismos presentes no leite têm origem em diversas fontes. A primeira contaminação ocorre no úbere do animal e a quantidade de microrganismo depende do estado de saúde do animal e das condições de higiene da ordenha. O leite recém-ordenhado, dentro dos limites, possui propriedades germicidas, devido à presença de lacteninas consideradas inibidoras de bactérias (MACEDO et al. 2001; SÁ, 2004).

Análises microbiológicas do leite fornecem informações úteis que refletem condições sob as quais o mesmo foi processado e armazenado.

Figueiredo et al. (2010), avaliando a característica microbiológica do leite de búfala no Estado do Pará, observaram que nenhuma das 20 amostras analisadas apresentou-se fora dos padrões exigidos pela legislação vigente, não apresentando contaminação por coliformes a $45^{\circ} \mathrm{C}$, nem por Staphylococcus aureus e Salmonella.

As búfalas são consideradas menos susceptíveis à mastite do que as vacas (LAU,1994), embora os microrganismos envolvidos na infecção sejam semelhantes (LANGONI et al., 2001). Os bubalinos apresentam os tetos relativamente mais pendulosos e longos, portanto mais sujeitos às injúrias do que os dos bovinos; contudo, nos bubalinos o ductus papilaris (ducto papilar) é mais musculoso, com maior quantidade de fibras e vasos sanguíneos, funcionando como uma barreira mais eficiente contra as infecções (LAU, 1994). Entretanto, Jorge et al., (2011) afirmam que as búfalas de alta produção leiteira são tão suscetíveis em contrair mastite como as vacas leiteiras e que é mais difícil de diagnosticar em búfalas do que em vacas. Na maioria dos casos, a mastite contagiosa é adquirida por falhas no manejo da ordenha.

Silva e Silva (1994) relataram que, embora a contagem total de células somáticas do leite normal de búfala fosse semelhante à do leite de vacas, a concentração e a eficiência funcional dos neutrófilos no leite de búfalas é maior, quando comparado com o leite de vacas. Além disso, o leite de búfalas apresenta maior atividade antibacteriana, por conter maior teor de lactoferrina, substância que torna o ferro iônico indisponível para o crescimento bacteriano.

Jorge et al. (2005) realizaram a contagem de células somáticas, em aparelho eletrônico Somacount 300 e verificaram que, das 544 amostras de leite de búfalas da raça Murrah, a média de células somáticas foi de 63.380 células $/ \mathrm{ml}$.

No Brasil, Vianni et al. (1990) determinaram que a prevalência de mastites em búfalas era de $8,81 \%$. Costa (2000) relata que em rebanhos bubalinos leiteiros do estado de São Paulo, a ocorrência de mastites subclínica e clínica representam, respectivamente $1,5 \%$ e $18,7 \%$, provocando diminuição na produção e na qualidade do leite.

Langoni et al. (2001) estudando a etiologia da mastite em búfalos verificaram que de 154 amostras de leite positivas ao California Mastitis Test (CMT), 83 (53,9\%) apresentaram crescimento bacteriano. Os microrganismos isolados foram: Corynebacterium bovis $(\mathrm{n}=26$; $31,3 \%)$; Staphylococcus epidermidis $(\mathrm{n}=25 ; 30,1(\mathrm{n}=4 ; \%)$; Streptococcus agalactiae $(\mathrm{n}=22 ; 26,5 \%)$; Staphylococcus aureus $(\mathrm{n}=4 ; 4,8 \%)$; Acinetobacter calcoaceticus $(\mathrm{n}=2$; 2,4\%); Pasteurella multocida ( $\mathrm{n}=2 ; 2,4 \%)$; e Bacillus spp $(\mathrm{n}=2 ; 2,4 \%)$.

\section{Considerações Finais}

A búfala tem grande potencial como animal para produção de leite, apresentando maior valor nutritivo e rendimento industrial quando comparados com o leite de vaca. A gordura é o constituinte do leite que apresenta maior valor econômico, sendo utilizada na produção de derivados.

Mundialmente, em relação ao volume produzido, o leite de búfala ocupa o segundo lugar em importância, depois do leite de vaca, seguido pelo de cabra e de ovelha que ocupam o terceiro e quarto lugares, respectivamente.

As búfalas são consideradas menos susceptíveis à mastite do que as vacas, embora os microrganismos envolvidos na infecção sejam semelhantes. Os bubalinos apresentam os tetos relativamente mais pendulosos e longos, portanto mais sujeitos às injúrias do que os dos bovinos; contudo, nos bubalinos o ductus papilaris (ducto papilar) é mais musculoso, com maior quantidade de fibras e vasos sanguíneos, funcionando como uma barreira mais eficiente contra as infecções.

\section{Referências}

1. AMARAL, F. R.; et al. Qualidade do leite de búfalas: composição. Revista Brasileira de Reprodução Animal, Belo Horizonte, v.29, p.106-110, 2005.

2. BRASIL. Ministério da Agricultura, Pecuária e Abastecimento - MAPA, Brasília, 2010.

3. CUNHA NETO, O.C. Avaliação do iogurte natural produzido com leite de búfala contendo diferentes níveis de gordura. 2003. 71f. Dissertação (Mestrado em Zootecnia) - Faculdade de Zootecnia e Engenharia de Alimentos da Universidade de São Paulo, Pirassununga, 2003 
4. CUNHA NETO, O.C.; OLIVEIRA C.A.F; HOTTA, R.M.; SOBRAL, P.J.A. Avaliação do iogurte natural produzido com leite de búfala contendo diferentes níveis de gordura. Ciência e Tecnologia de Alimentos, Campinas, v.3, n.25, p.448-453, jul/ set., 2005.

5. DUARTE, J.M.C., et al. Efeitos ambientais sobre a produção no dia do controle e características físico-químicas do leite em um rebanho bubalino no Estado de São Paulo, Brasil. Revista Instituto de Laticínios Candido Tostes, v.56, n.5, p.16-19, 2001.

6. DUBEY P.C., et al. Factors affecting composition of milk of buffaloes. Indian Journal of Animal Sciences, v.67, n.9, p.802-804, 1997.

7. FAO. FAOSTAT: agriculture database. Rome, 2007. Disponível em: <http://faostat. fao.org/default.aspx>. Acesso em: 23 ago. 2007.

8. FIGUEIREDO, E.L., JUNIOR, J.B.L., TORO, M.J.U. Caracterização físico-química e microbiológica do leite de búfala "in natura" produzido no Estado do Pará. Revista Brasileira de Tecnologia Agroindustrial, v.04, n.01, p.19-28, 2010

9. FREITAS, J.A. Qualidade do leite frente seu beneficiamento e obtenção de derivados In: Seminário de Zootecnia, I. 2001, Belém-Pará. Faculdade de Ciências Agrárias do Pará. Belém, set. 2001

10. GONÇALVES, C.A., VIEIRA, L.C. Obtenção e higienização do leite in natura. Empresa Brasileira de Pesquisa Agropecuária, Embrapa Amazônia Oriental, Belém: Documento 141. 2002. 28p.

11. JORGE, A.M., et al. Correlação entre o California Mastitis Test (CMT) e a Contagem de Células Somáticas (CCS) do leite de Búfalas Murrah. R. Bras. Zootec., v.34, n.6, p.2039-2045, 2005

12. JORGE, A.M., COUTO, A.G., CRUDELI, G.A., PATIÑO, E.M. Produção de búfalas de leite. Botucatu: FEPAF, 2011. 181p.

13. LANGONI, H., et al. Etiologia e sensibilidade bacteriana da mastite subclínica em búfalos (Bubalus bubalis). ARS Veterinária, Jaboticabal, v.17, n.3, p.213-217, 2001.

14. LAU, H.D. Important economic diseases in buffaloes. In: WORLD BUFFALO CONGRESS, 4., São Paulo, 1994, Anais. São Paulo: Associação Brasileira de Criadores de Búfalos, 1994. p.209-220.

15. MACEDO, M.P., et al. Composição Físico-Química e Produção do Leite de Búfalas da Raça Mediterrâneo no Oeste do Estado de São Paulo, São Paulo, SP, Rev. Bras. Zootec., Viçosa, SP, v.30, n.3, p.1084-1088, 2001

16. MESQUITA, A.J.de, et al. Qualidade físico-química e microbiológica do leite cru bubalino. Goiânia: Ed. da UFG, 2002.
17. NASCIMENTO, C.N.B.; CARVALHO, L.O.M. Criação de Búfalos: Alimentação, Manejo, Melhoramento e Instalações. Brasília: EMBRAPA-SPI, 1993. 403 p.

18. OLIVEIRA, R. L. Ácidos graxos de cadeia longa (CLA) no leite e seus benefícios para o consumo. In: Congresso Nacional de Zootecnia, 14. Brasília, 2004.

19. ROSATI, A.; VAN VLECK, L.D. Estimation of genetic parameters for milk, fat, protein and mozzarella cheese production in the italian river buffalo population. Livest. Prod. Sci., v.74, n.2, p.185-190, 2002.

20. SÁ, E. Análises realizadas para o controle da qualidade de leite in natura de acordo com os parâmetros legais. Revista Leite \& Derivados, ano XIV, n.81, p.67-72. 2004

21. SANTA ROSA, R.M.S. logurte de leite de búfala adicionado de polpa de frutas da Amazônia: parâmetros de qualidade. 2011. Tese (Doutorado em Higiene Veterinária e Processamento Tecnológico de Produtos de Origem Animal) - Universidade Federal Fluminense, 2011. 85p

22. SÃO PAULO (Estado). Secretaria de Agricultura e Abastecimento. Resolução SAA n 24 de 01 de agosto de 1994: Dispõe sobre as normas técnicas de produção e classificação dos produtos de origem animal e as relativas às atividades de fiscalização e inspeção dos produtos de origem animal. Disponível em <http:cda.sp.gov.br/ legislação >. Acesso em: 02 set. 2011.

23. SILVA, M. S. T.; et al. Programa de incentivo a criação de búfalos por pequenos produtores - PRONAF. Pará, agosto de 2003. Disponível em: <www.cpatu.br/bufalo> Acesso em: 20 de fev. de 2011.

24. SILVA, I.D.; SILVA, K.F.S.T. Total and differential cell counts in buffalo (Bubalus bubalis) milk. Buffalo J., v.10, n.2, p.133-137, 1994.

25. SINDHU, J.S; SINGHAL, O.P. Qualitative aspects of buffalo milk constituents for products technology. II World Buffalo Congress, New Delhi - India, p.263-81, 1988.

26. TEIXEIRA, L.V.; BASTIANETTO, E.; OLIVEIRA, D.A.A. Leite de Búfala na Indústria de Produtos Lácteos. Rev. Bras. Reprod. Anim., Belo Horizonte, MG, v.29, n.2, p.96-100, abril/jun, 2005.

27. TONHATI, H., et al. Controle leiteiro em búfalas. In: II SIMPÓSIO NACIONAL DE MELHORAMENTO ANIMAL. Uberaba, Anais, SBMA, v.1, p. 53-8,1998.

28. TONHATI, H., et al. Parâmetros genéticos para a produção de leite, gordura e proteína em bubalinos. Revista Sociedade Brasileira de Zootecnia. Viçosa, v.29, n.6, p.1320-1325, Suplemento1, 2000

29. VIANNI, M.C.E.; NADER FILHO, A.; ROSSETI, D.J.G., et al. Eficiência do Califórnia Mastitis Test (CMT) na estimativa do número de células somáticas do leite bubalino. Ciênc. Vet., v.4, n.2, p.3-4, 1990. 